\title{
Longitudinal Changes in High Molecular Weight Serum Adiponectin Levels in Healthy Infants
}

\author{
SATOSHI HIBINO, KAZUO ITABASHI, YUYA NAKANO, MAKOTO INOUE, DAISUKE TANAKA, AND TAKESHI MARUYAMA
}

\begin{abstract}
Department of Pediatrics [S.H., K.I., Y.N.], Showa University School of Medicine, Tokyo 142-8666, Japan; Children's Medical Center [M.I.], Showa University Northern Yokohama Hospital, Yokohama 224-8503, Japan; Department of Pediatrics [D.T.], Showa University Toyosu Hospital, Tokyo 135-8577, Japan; Department of Pediatrics [T.M.], Keiai Hospital, Obihiro 080-0803, Japan
\end{abstract}

\begin{abstract}
To determine the factors associated with high molecular weight adiponectin (HMW-ad) levels during the first year of life, the longitudinal changes in serum HMW-ad were investigated from birth to 12 mo of age. The total adiponectin levels, HMW-ad, and leptin were measured longitudinally from birth to 12 mo of age in 56 healthy infants ( $\geq 35 \mathrm{wk}$ of gestation). Serum HMW-ad levels were positively correlated with total adiponectin levels $\left(R^{2}=0.93, p<\right.$ $0.0001)$. Serum HMW-ad levels at birth, six, and 12 mo were $13.7 \pm$ 0.9 (mean $\pm \mathrm{SE}$ ), $13.3 \pm 0.8$, and $7.7 \pm 0.5 \mu \mathrm{g} / \mathrm{mL}$, respectively. The levels at 12 mo were significantly lower than those at birth and 6 mo, respectively. In a multiple regression analysis, the HMW-ad levels at 12 mo were found to be related only to cord blood HMW-ad levels $(\beta=0.680, p<0.001)$ and not to any other factors. These results imply that postnatal production of HMW-ad at least during infancy may be regulated before birth. Further study is necessary to determine whether cord blood HMW-ad has an effect and whether it is involved in the development of metabolic syndrome. (Pediatr Res 65: 363-366, 2009)
\end{abstract}

A diponectin is a hormone produced by adipocytes. Decreased adiponectin production is suggested to be related to metabolic syndrome, including type 2 diabetes $(1,2)$, obesity (3), hypertension (4), and dyslipidemia (5). High concentrations of circulating adiponectin reportedly have positive health effects such as reduction in proinflammatory cytokine levels (6), an improvement in insulin sensitivity (7), and an increase in fatty acid metabolism (8). Recently, several investigators reported much higher plasma adiponectin concentrations in cord blood than in the mother (9-12) and in nonobese adults aged 23-50 y (13). Numerous previous studies have also documented a positive correlation between the cord blood levels and the birth weight in newborn infants (10-14), thus suggesting that these adipocytokines might play a key role in fetal development.

Adiponectin has intriguing structural properties that may influence the in vivo activity of the protein. The native protein circulates in serum as low molecular weight, middle molecular weight, and high molecular weight multimers (15). Recent investigations have revealed that high molecular weight adiponectin (HMW-ad) may be an active form of the protein because it is a better determinant of glucose intolerance (16) and confers

Received August 13, 2008; accepted October 20, 2008.

Correspondence: Kazuo Itabashi, M.D., Department of Pediatrics, Showa University School of Medicine, 1-5-8 Hatanodai, Shinagawa-ku, Tokyo 142-8666, Japan; e-mail: kitaba@med.showa-u.ac.jp

Supported by a grant from the Ministry of Health, Labor and Welfare, Japan. vascular protective activities (17). Phagocytosis of apoptotic cells by macrophages and subsequent IL- 8 production are suppressed by HMW-ad (18). Both cord blood HMW-ad and leptin levels were significant predictors of birth weight in our previous study. There is a significant relationship between the concentration of HMW-ad and leptin. This finding suggested that HMW-ad and leptin might synergistically regulate fetal growth (19). Despite a better understanding of the role of HMW-ad in adults, no information regarding the changes in serum HMW-ad levels and factors correlated to HMW-ad concentrations during infancy are available. Therefore, the longitudinal changes in serum HMW-ad were investigated from birth to 12 mo to determine the factors that are associated with the HMW-ad levels during this time of development.

\section{SUBJECTS AND METHODS}

The Ethics Committee at Keiai Hospital approved the study protocol. The subjects were recruited at the Obihiro Keiai Hospital (primary obstetric center) between May 1, 2005 and September 30, 2006. Before delivery, the objectives of this study were explained to the parents and informed written consent was obtained. The infants whose mothers had any complications, such as gestational diabetes mellitus, thyroid disease, pregnancy-induced hypertension, and autoimmune diseases were excluded. The gestational age was determined according to the first trimester crown-rump length scan. Fifty-six infants appropriate for gestational age who were born without complications at the gestational age of $35 \mathrm{wk}$ or more were recruited for this study. Of the 56 infants, 5 infants were born at less than $37 \mathrm{wk}$ of gestation. All the infants were followed up to 12 mo of age. These infants visited the hospital at 6 and 12 mo to undergo anthropometric measurement, blood collection, consultation, and to find out the particulars of how the infants were being fed (breast or formula fed), when and whether they were weaned or whether they were given any solid foods.

The infants recruited in this study were supplemented with cow's milkbased formula when their mother considered that intake of breast milk was not sufficient for their infants. Of the 56 subjects, 27 infants were exclusively fed breast milk, four infants were fed a combination of breast and formula milk, and 25 infants were fed formula milk at 12 mo of age. The introduction of solid food and its contents were left to the mother's discretion. The following issues were investigated.

Anthropometric measurements. General physical measurements, including body weight and length, were determined at birth, 6 and 12 mo after birth by experienced nurses. Their mother's body weight and height before pregnancy were self-reported. The body weight after pregnancy was measured to the nearest $0.1 \mathrm{~kg}$ value on a digital scale at each antenatal visit. Weight gains during pregnancy were calculated by the difference between body weight before pregnancy and body weight measured until delivery.

Determination of serum total adiponectin, $\mathrm{HMW}$-ad, and leptin concentrations. To determine total serum adiponectin (T-ad), HMW-ad, and leptin levels, blood was collected from the umbilical vein at birth and the antecubital

Abbreviations: HMW-ad, high molecular weight adiponectin; T-ad, total adiponectin 
vein at 6 and 12 mo. These samples were centrifuged and the serum collected was cryopreserved at $-40^{\circ} \mathrm{C}$ until analysis. At 6 and $12 \mathrm{mo}$, the blood was generally collected 2 or $3 \mathrm{~h}$ after feeding. Serum T-ad and HMW-ad concentrations were determined by ELISA using a commercial kit (Daiichi Pure Chemicals, Tokyo, Japan) and the serum leptin levels were calculated using a commercial RIA kit (Linco research, St. Louis, MO). Intra- and interassay variation coefficients for T-ad and HMW-ad were $<4 \%$ and those for leptin were $<8 \%$.

The data were analyzed using the Dr. SPSS for Windows statistical package (SPSS Japan, Tokyo). The results using continuous variables were presented as the mean \pm SE. A comparison of leptin concentrations between male and female subjects was performed using the Mann-Whitney test. The longitudinal changes in T-ad, HMW-ad, leptin, and the ratio of HMW-ad vs. $\mathrm{T}$-ad of umbilical cord blood and the blood collected at 6 and 12 mo were determined using Friedman's test and a post hoc test of the data were conducted using the Wilcoxon test (significant difference $p<0.0169$ ). A multiple regression analysis assessed the influence of the multiple variables (gestational age, birth weight, sex, the duration of breast feeding, anthropometric measurements at 12 mo of life, maternal anthropometric measurements, and cord blood adipocytokines) on serum adipokines at 12 mo. The differences were considered statistically significant when the $p$ values were $<0.05$.

\section{RESULTS}

Clinical characteristics of the subjects. The anthropometric measurements of mothers before pregnancy and their weight gain until delivery, as well as the gestational age, birth weight, and anthropometric measurements of the subjects at birth, 6 , and 12 mo are shown in Table 1.

Laboratory measurements at birth, 6 and 12 mo. There were no significant differences in T-ad, HMW-ad, and the ratio of HMW-ad to T-ad at birth, 6, and 12 mo between male and female subjects. Serum T-ad, HMW-ad, and the ratio of HMW-ad to T-ad in all subjects at 12 mo were significantly lower than those at birth and 6 mo. Comparing these laboratory measurements at birth with those at 12 mo there was approximately a $34 \%$ reduction in $\mathrm{T}-\mathrm{ad}$, a $43 \%$ reduction in HMW-ad, and a $17 \%$ reduction in the ratio of HMW-ad to $\mathrm{T}$-ad. Although there was a significant difference in cord blood leptin levels between male and female subjects $(p=0.012)$, these differences no longer prevailed at 6 and 12 mo of age (Table 2).

Table 1. Clinical characteristics of the study subjects

\begin{tabular}{lc}
\hline & Mean \pm SE \\
\hline Mother & \\
Body weight before pregnancy $(\mathrm{kg})$ & $53.3 \pm 1.1$ \\
Height $(\mathrm{cm})$ & $159.2 \pm 0.7$ \\
BMI before pregnancy $\left(\mathrm{kg} / \mathrm{m}^{2}\right)$ & $21.0 \pm 0.4$ \\
Weight gain during pregnancy $(\mathrm{kg})$ & $9.8 \pm 0.5$ \\
At birth & \\
Gestational age $(\mathrm{wk})$ & $39.0 \pm 0.2$ \\
Birth weight $(\mathrm{g})$ & $3052.8 \pm 59.4$ \\
Body length $(\mathrm{cm})$ & $48.9 \pm 0.3$ \\
Sex (male/female) & $29 / 27$ \\
6 mo of life & \\
Body weight $(\mathrm{g})$ & $7541.8 \pm 122.2$ \\
Body length $(\mathrm{cm})$ & $66.0 \pm 0.4$ \\
BMI $\left(\mathrm{g} / \mathrm{cm}^{2}\right)$ & $17.2 \pm 0.2$ \\
12 mo of life & \\
Body weight $(\mathrm{g})$ & $9097.3 \pm 132.7$ \\
Body length $(\mathrm{cm})$ & $72.7 \pm 0.4$ \\
BMI $\left(\mathrm{kg} / \mathrm{m}^{2}\right)$ & $17.2 \pm 0.2$ \\
Duration of breast feeding $(\mathrm{mo})$ & $9.1 \pm 0.5$ \\
\hline
\end{tabular}

BMI, body mass index.
The HMW-ad levels at birth, 6, and 12 mo had significant positive correlations with T-ad (at birth $R=0.956, p<$ 0.0001 ; 6 mo $R=0.969, p<0.0001$; and 12 mo $R=0.966$, $p<0.0001)$. The ratio of HMW-ad to T-ad at birth, 6 , and 12 mo correlated with T-ad (at birth $R=0.536, p<0.0001 ; 6$ mo $R=0.398, p=0.02$; and 12 mo $R=0.558, p<0.0001$ ).

Factors related to serum $\mathrm{T}$-ad, HMW-ad, and leptin levels at 12 mo. In a simple regression analysis, cord blood T-ad positively related to serum T-ad levels at $12 \mathrm{mo}(R=0.609$, $p<0.0001)$. Similarly, cord blood HMW-ad positively related to HMW-ad levels at $12 \mathrm{mo}(R=0.547, p<0.0001)$. Moreover, the ratio of HMW-ad to T-ad in cord blood positively related to the levels at 12 mo $(R=0.267, p=0.046)$. However, the mothers' anthropometric measurements, the subjects' anthropometric measurements at $12 \mathrm{mo}$, sex, gestational age, birth weight, and the duration of breast-feeding were not related to the laboratory data at $12 \mathrm{mo}$. In a multiple regression analysis aimed to identify independent predictors of serum adiponectin levels at $12 \mathrm{mo}$, T-ad, HMW-ad, and the ratio of HMW-ad to T-ad at $12 \mathrm{mo}$ had a significant positive correlation with T-ad $(\beta=0.731, p<0.0001)$, HMW-ad $(\beta=$ $0.680, p<0.0001)$ and the ratio of HMW-ad to T-ad $(\beta=0.296$, $p=0.045$ ) in cord blood, respectively. In contrast to adiponectin, the serum leptin levels at $12 \mathrm{mo}$ had a positive correlation with BMI measurements at $12 \mathrm{mo}(\beta=0.462, p=0.020)$ (Table 3$)$.

\section{DISCUSSION}

HMW-ad is superior to T-ad to predict the development of insulin resistance, metabolic syndrome, and coronary disease (20-22). There were strong positive associations between serum T-ad and HMW-ad levels at birth, 6, and 12 mo in our subjects. The ratio of HMW-ad to T-ad at birth, 6, and 12 mo positively correlated with T-ad at birth, 6 , and $12 \mathrm{mo}$, respectively. Therefore, a lower T-ad level was associated with a lower HMW-ad and ratio of HMW-ad to T-ad. These findings are consistent with the previous report (23).

In this study, serum T-ad and HMW-ad levels in cord blood and at 6 mo were higher than those at $12 \mathrm{mo}$ after birth. But, the levels measured at 12 mo seem to be higher than those measured at the age of 9-10 y as reported by Nishimura et al. (24). The hyperadiponectinemia in the cord blood of our subjects is consistent with previous reports $(13,14,19)$. It has been hypothesized that hyperadiponectinemia might be related to a lack of negative feedback on adiponectin production in visceral-thin neonates and/or might be related to the presence of brown adipose tissue in human neonates because brown adipose tissue may be the source of the abundant adiponectin concentrations at birth (11). A recent report indicated that adiponectin is expressed in tissues of mesodermic origin. These authors speculated that the unexpected pattern of adiponectin expression observed in the human fetus during midand late gestation may account for the high adiponectin concentrations found in cord blood (10).

This study demonstrated that serum levels of $\mathrm{T}$-ad and HMW-ad at birth were maintained until 6 mo. BMI commonly increases rapidly during the first 6 mo of age. This change in the BMI is related to the fact that adipose tissue rapidly 
Table 2. Serum adipocytokines at birth, six, and $12 \mathrm{mo}$

\begin{tabular}{|c|c|c|c|c|}
\hline Serum concentration & Cord blood & 6 mo of life & 12 mo of life & $p$ \\
\hline Total adiponectin $(\mu \mathrm{g} / \mathrm{mL})$ & $18.9 \pm 1.1$ & $18.3 \pm 1.0$ & $12.4 \pm 0.6^{*}, \dagger$ & $<0.0001$ \\
\hline HMW-adiponectin $(\mu \mathrm{g} / \mathrm{mL})$ & $13.7 \pm 0.9$ & $13.3 \pm 0.8$ & $7.7 \pm 0.5^{*}, \dagger$ & $<0.0001$ \\
\hline HMW-ad/T-ad ratio & $0.71 \pm 0.01$ & $0.71 \pm 0.01$ & $0.60 \pm 0.01 *, \dagger$ & $<0.0001$ \\
\hline \multicolumn{5}{|c|}{ Leptin (ng/mL) [median (range)] } \\
\hline Male & $1.9(0.7-11.4) \ddagger$ & $4.1(1.6-13.4)$ & $2.3(1.3-3.9) \dagger$ & 0.001 \\
\hline Female & $5.2(0.7-20.2)$ & $3.7(2.4-5.7)$ & $2.4(1.3-3.6)^{*}, \dagger$ & 0.001 \\
\hline
\end{tabular}

* 12 mo vs. cord blood $(p<0.01)$.

$\dagger 12$ mo vs. 6 mo $(p<0.01)$.

\$ Male vs. female $p=0.012$.

HMW-ad, high molecular weight adiponectin; T-ad, total adiponectin.

Table 3. Multiple regression analysis of factors related to serum adipocytokines at $12 \mathrm{mo}$

\begin{tabular}{|c|c|c|c|c|c|c|c|c|}
\hline \multirow[b]{3}{*}{ Variables } & \multicolumn{8}{|c|}{ Serum levels at $12 \mathrm{mo}$ of life } \\
\hline & \multicolumn{2}{|c|}{ Total adiponectin } & \multicolumn{2}{|c|}{ HMW-adiponectin } & \multicolumn{2}{|c|}{$\begin{array}{c}\text { HMW-ad/T-ad } \\
\text { ratio }\end{array}$} & \multicolumn{2}{|c|}{ Leptin } \\
\hline & $\beta$ & $p$ & $\beta$ & $p$ & $\beta$ & $p$ & $\beta$ & $p$ \\
\hline Cord blood total adiponectin $(\mu \mathrm{g} / \mathrm{ml})$ & 0.731 & $<0.0001$ & - & - & - & - & - & - \\
\hline Cord blood HMW-adiponectin $(\mu \mathrm{g} / \mathrm{mL})$ & - & - & 0.680 & $<0.0001$ & - & - & - & - \\
\hline Cord blood HMW-ad/T-ad ratio & - & - & - & - & 0.296 & 0.045 & - & - \\
\hline Cord blood leptin (ng/mL) & - & - & - & - & - & - & 0.122 & 0.456 \\
\hline BMI before pregnancy $\left(\mathrm{kg} / \mathrm{m}^{2}\right)$ & -0.005 & 0.968 & 0.006 & 0.962 & 0.219 & 0.133 & -0.082 & 0.569 \\
\hline Weight gain during pregnancy $(\mathrm{kg})$ & 0.123 & 0.360 & 0.085 & 0.546 & -0.051 & 0.764 & 0.049 & 0.771 \\
\hline Gestational age (week) & -0.181 & 0.363 & -0.141 & 0.499 & -0.158 & 0.534 & -0.364 & 0.158 \\
\hline Birth weight $(\mathrm{g})$ & -0.077 & 0.685 & -0.149 & 0.456 & -0.184 & 0.455 & 0.204 & 0.440 \\
\hline Sex (male) & 0.191 & 0.162 & 0.141 & 0.325 & -0.144 & 0.407 & 0.044 & 0.798 \\
\hline Body weight at $12 \mathrm{mo}(\mathrm{g})$ & -0.210 & 0.238 & -0.198 & 0.296 & 0.042 & 0.856 & -0.320 & 0.152 \\
\hline BMI at $12 \mathrm{mo}\left(\mathrm{kg} / \mathrm{m}^{2}\right)$ & -0.038 & 0.806 & -0.067 & 0.678 & -0.009 & 0.963 & 0.462 & 0.020 \\
\hline Duration of breast feeding (months) & -0.096 & 0.397 & -0.156 & 0.194 & -0.171 & 0.249 & 0.060 & 0.675 \\
\hline
\end{tabular}

HMW-ad, high molecular weigtht adiponectin; T-ad, total adiponectin; BMI, body mass index.

expands as a result of an increase in the size and number of adipocytes. Adiponectin expression increases with the differentiation of adipocytes (25). Therefore, one reason why serum T-ad and HMW-ad levels at birth were sustained until 6 mo might be related to the degree of adipose tissue development during the first 6 mo. Adiponectin and leptin were clearly detectable in breast milk (26). Therefore, it is hypothesized that infants may be exposed to adipocytokines and this might be related to serum levels of these adipocytokines. However, the duration of breast-feeding was not a factor affecting adiponectin and leptin levels at 12 mo of age in this study. Dietary long chain polyunsaturated fatty acids may increase serum adiponectin levels (27). Because there was no information available concerning the intake of long chain polyunsaturated fatty acids from breast milk and solid food, the effects of dietary long chain polyunsaturated fatty acids on serum adiponectin levels are undetermined.

Iñiguez et al. (28) reported that $\sim 25 \%$ reduction is observed in adiponectin levels from 1 to $2 \mathrm{y}$ of age. However, the longitudinal pattern in changes of serum adiponectin levels during infancy remains unknown. Recently, Inami et al. (29) demonstrated that levels of adiponectin at 1 mo are higher than those in cord blood. Hence, serum adiponectin levels might not be constant during the first 6 mo. Comparing the laboratory measurements at 6 to those at 12 mo, demonstrated that there was approximately a $32 \%$ reduction in $\mathrm{T}-\mathrm{ad}$, a $42 \%$ reduction in HMW-ad, and a $17 \%$ reduction in the ratio of HMW-ad to T-ad. The reduction of HMW-ad predominantly contributed to the reduction of T-ad levels at $12 \mathrm{mo}$. This physiologic change may predominantly be because of a downregulation of HMW-ad. However, the mechanism responsible for reducing HMW-ad levels remains undetermined.

The serum leptin levels at 12 mo were positively associated with the BMI at $12 \mathrm{mo}$. This finding suggests that serum leptin levels during infancy may be affected by developing adipose tissue. Conversely, no relationship between serum adiponectin levels and adiposity at 12 mo was observed in the current subjects. Previous reports also observed no association between serum adiponectin levels and adiposity at 1 mo of life (29) and at 2 y of age (30). The absence of an inverse association between serum adiponectin and adiposity seen in adults or positive association at birth may indicate different regulation of adiponectin production during infancy.

A positive association between serum adiponectin levels in cord blood and at $12 \mathrm{mo}$ in this study suggests that the postnatal serum adiponectin levels until 12 mo after birth may be programmed in utero; however, there is no data to support this hypothesis at the moment. Recent investigation has suggested that several single nucleotide polymorphisms at the adiponectin locus may also have influence on adiponectin levels (30). Rothenbacher et al. (30) demonstrated that children with the adiponectin single nucleotide polymorphism (-11377CG and GG) have higher adiponectin levels at birth and at 2 y than CC homozygous. The positive relationship between serum adiponectin levels in cord blood and those at 12 mo of life is a new finding. It would be very interesting to 
understand how serum adiponectin at birth is involved in the development of metabolic syndrome if the primary process in the metabolic syndrome is the reduction in adiponectin production (25). To examine this more carefully as well as to study the physiologic significance of adiponectin during infancy, it will be necessary to follow these infants on a long-term basis.

In brief, this study demonstrated that serum HMW-ad levels were dependent on T-ad levels, serum T-ad, HMW-ad levels, and the ratio of HMW-ad to T-ad in healthy infants sustained at least for the first $6 \mathrm{mo}$, and those at $12 \mathrm{mo}$ had no relationship to anthropometric measurements. In addition, serum adiponectin levels in cord blood had a positive relationship with those at $12 \mathrm{mo}$. This result suggests that postnatal production of HMW-ad at least during infancy may be regulated before birth. Further study is necessary to the extent cord blood HMW-ad has an effect, and whether it is involved in the development of metabolic syndrome.

\section{REFERENCES}

1. Spranger J, Kroke A, Mohlig M, Bergmann MM, Ristow M, Boeing H, Pfeiffer AF 2003 Adiponectin and protection against type 2 diabetes mellitus. Lancet 361:226228

2. Daimon M, Oizumi T, Saitoh T, Kameda W, Hirata A, Yamaguchi H, Ohnuma H, Igarashi M, Tominaga M, Kato T 2003 Decreased serum levels of adiponectin are a risk factor for the progression to type 2 diabetes in the Japanese population: the Funagata study. Diabetes Care 26:2015-2020

3. Arita Y, Kihara S, Ouchi N, Takahashi M, Maeda K, Miyagawa J, Hotta K, Shimomura I, Nakamura T, Miyaoka K, Kuriyama H, Nishida M, Yamashita S, Okubo K, Matsubara K, Muraguchi M, Ohmoto Y, Funahashi T, Matsuzawa Y 1999 Paradoxical decrease of an adipose-specific protein adiponectin in obesity. Biochem Biophys Res Commun 257:79-83

4. Iwashima Y, Katsuya T, Ishikawa K, Ouchi N, Ohishi M, Sugimoto K, Fu Y, Motone M, Yamamoto K, Matsuo A, Ohashi K, Kihara S, Funahashi T, Rakugi H, Matsuzawa Y, Ogihara T 2004 Hypoadiponectinemia is an independent risk factor for hypertension. Hypertension 43:1318-1323

5. Matsubara M, Maruoka S, Katayose S 2002 Decreased plasma adiponectin concentrations in women with dyslipidemia. J Clin Endocrinol Metab 87:2764-2769

6. Wulster-Radcliffe MC, Ajuwon KM, Wang J, Christian JA, Spurlock ME 2004 Adiponectin differentially regulates cytokines in porcine macrophages. Biochem Biophys Res Commun 316:924-929

7. Combs TP, Berg AH, Obici S, Scherer PE, Rossetti L 2001 Endogenous glucose production is inhibited by the adipose-derived protein Acrp30. J Clin Invest 108:1875-1881

8. Yamauchi T, Kamon J, Minokoshi Y, Ito Y, Waki H, Uchida S, Yamashita S, Noda M, Kita S, Ueki K, Eto K, Akanuma Y, Froguel P, Foufelle F, Ferre P, Carling D, Kimura S, Nagai R, Kahn BB, Kadowaki T 2002 Adiponectin stimulates glucose utilization and fatty-acid oxidation by activating AMP-activated protein kinase. Nat Med 8:1288-1295

9. Lindsay RS, Walker JD, Havel PJ, Hamilton BA, Calder AA, Johnstone FD; Scottish Multicentre Study of Diabetes Pregnancy 2003. Adiponectin is present in cord blood but is unrelated to birth weight. Diabetes Care 26:2244-2249

10. Corbetta S, Bulfamante G, Cortelazzi D, Barresi V, Cetin I, Mantovani G, Bondioni S, Beck-Peccoz P, Spada A 2005 Adiponectin expression in human fetal tissues during mid- and late gestation. J Clin Endocrinol Metab 90:2397-2402
11. Sivan E, Mazaki-Tovi S, Pariente C, Efraty Y, Schieff E, Hemi R, Kanety H 2003 Adiponectin in human cord blood: relation to fetal birth weight and gender. J Clin Endocrinol Metab 88:5656-5660

12. Chan TF, Yuan SS, Chen HS, Guu CF, Wu LC, Yeh YT, Chung YF, Jong SB, Su JH 2004 Correlations between umbilical and maternal serum adiponectin levels and neonatal birth weights. Acta Obstet Gynecol Scand 83:165-169

13. Kotani Y, Yokota I, Kitamura S, Matsuda J, Naito E, Kuroda Y 2004 Plasma adiponectin levels in newborns are higher than those in adults and positive correlated with birth weight. Clin Endocrinol (Oxf) 61:418-423

14. Tsai PJ, Yu CH, Hsu SP, Lee YH, Chio CH, Hsu YW, Ho SC, Chu CH 2004 Cord plasma concentrations of adiponectin and leptin in healthy neonates: positive correlation with birth weight and neonatal adiposity. Clin Endocrinol (Oxf) 61:88-93

15. Waki H, Yamauchi T, Kamon J, Ito Y, Uchida S, Kita S, Hara K, Hada Y, Vasseur F, Froguel P, Kimura S, Nagai R, Kadowaki T 2003 Impaired multimerization of human adiponectin mutants associated with diabetes. J Biol Chem 278:4035240363

16. Fisher FF, Trujillo ME, Hanif W, Barnett AH, McTernan PG, Scherer PE, Kumar S 2005 Serum high molecular weight complex of adiponectin correlates better with glucose tolerance than total serum adiponectin in Indo-Asian males. Diabetologia 48:1084-1087

17. Kobayashi H, Ouchi N, Kihara S, Walsh K, Kumada M, Abe Y, Funahashi T, Matsuzawa Y 2004 Selective suppression of endothelial cell apoptosis by the high molecular weight form of adiponectin. Circ Res 94:e27-e31

18. Saijo S, Nagata K, Nakano Y, Tobe T, Kobayashi Y 2005 Inhibition by adiponectin of IL-8 production by human macrophages upon culturing with late apoptotic cells. Biochem Biophys Res Commun 334:1180-1183

19. Inoue M, Itabashi K, Nakano Y, Nakano Y, Tobe Y 2008 High-molecular-weight adiponectin and leptin levels in cord blood are associated with anthropometric measurements at birth. Horm Res 70:268-272

20. Aso Y, Yamamoto R, Wakabayashi S, Uchida T, Takayanagi K, Takebayashi K, Okuno T, Inoue T, Node K, Tobe T, Inukai T, Nakano Y 2006 Comparison of serum high-molecular weight (HMW) adiponectin with total adiponectin concentrations in type 2 diabetic patients with coronary artery disease using a novel enzyme-linked immunosorbent assay to detect HMW adiponectin. Diabetes 55:1954-1960

21. Araki S, Dobashi K, Kubo K, Asayama K, Shirahata A 2006 High molecular weight, rather than total, adiponectin levels better reflect metabolic abnormalities associated with childhood obesity. J Clin Endocrinol Metab 91:5113-5116

22. Hara K, Horikoshi M, Yamauchi T, Yago H, Miyazaki O, Ebinuma H, Imai Y, Nagai R, Kadowaki T 2006 Measurement of the high-molecular weight form of adiponectin in plasma is useful for the prediction of insulin resistance and metabolic syndrome. Diabetes Care 29:1357-1362

23. Körner A, Wabitsch M, Seidel B, Fischer-Posovszky P, Berthold A, Stumvoll M, Blüher M, Kratzsch J, Kiess W 2005 Adiponectin expression in humans is dependent on differentiation of adipocytes and down-regulated by humoral serum components of high molecular weight. Biochem Biophys Res Commun 337:540-550

24. Nishimura R, Morimoto A, Matsudaira T, Miyashita Y, Sano H, Shirasawa T, Takahashi E, Tajima N 2007 Ratio of high-, medium-, and low-molecular weight serum adiponectin to the total adiponectin value in children. J Pediatr 151:545-547

25. Körner A, Kratzsch J, Gausche R, Schaab M, Erbs S, Kiess W 2007 New predictors of the metabolic syndrome in children-role of adipocytokines. Pediatr Res 61:640645

26. Savino F, Liguori SA 2008 Update on breast milk hormones: leptin, ghrelin and adiponectin. Clin Nutr 27:42-47

27. Siahanidou T, Margeli A, Lazaropoulou C, Karavitakis E, Papassotiriou I, Mandyla H 2008 Circulating adiponectin in preterm infants fed long-chain polyunsaturated fatty acids (LCPUFA)-supplemented formula: a randomized controlled study. Pediatr Res 63:428-432

28. Iñiguez G, Soto N, Avila A, Salazar T, Ong K, Dunger D, Mericq V 2004 Adiponectin levels in the first two years of life in a prospective cohort: relations with weight gain, leptin levels and insulin sensitivity. J Clin Endocrinol Metab 89:55005503

29. Inami I, Okada T, Fujita H, Makimoto M, Hososno S, Minato M, Takahashi S, Harada K, Yamamoto T 2007 Impact of serum adiponectin concentration on body size and early postnatal growth. Pediatr Res 61:604-606

30. Rothenbacher D, Nieters A, Weyermann M, Brenner H 2007 Adiponectin polymorphisms, cord blood levels of adiponectin, and body composition. J Allergy Clin Immunol 120:469-470 